\title{
PERAN SHOPPING EMOTION DALAM MEMEDIASI PENGARUH ATMOSFER RITEL DAN PROMOSI TERHADAP IMPULSE BUYING
}

\author{
Ni Putu Krisna Diah Rani ${ }^{1}$ \\ Ni Made Purnami ${ }^{2}$
${ }^{1,2}$ Fakultas Ekonomi dan Bisnis Universitas Udayana, Bali, Indonesia
e-mail: krisnadiah12@gmail.com

\begin{abstract}
ABSTRAK
Tujuan penelitian ini adalah untuk menjelaskan pengaruh atmosfer ritel, dan promosi terhadap emosi, untuk menjelaskan pengaruh atmosfer ritel, promosi, dan emosi terhadap impulse buying, untuk menjelaskan peran emosi sebagai pemediasi atas hubungan antara atmosfer ritel dan promosi terhadap impulse buying pada konsumen Hypermart Mall Bali Galeria. Populasi dalam penelitian ini adalah seluruh konsumen yang pernah berbelanja di Hypermart Mall Bali Galeria dan pernah melakukan Impulse Buying. Metode penentuan sampel yang digunakan adalah purposive sampling. Sampel yang dipilih dalam penelitian ini sebanyak 108 responden. Data di analisis menggunakan teknik analisis jalur. Berdasarkan hasil penelitian menunjukkan bahwa atmosfer ritel, dan promosi berpengaruh positif terhadap emosi. Atmosfer ritel, promosi, dan emosi berpengaruh positif terhadap impulse buying. Emosi memediasi hubungan antara atmosfer ritel dan promosi terhadap impulse buying pada konsumen Hypermart Mall Bali Galeria.
\end{abstract}

Kata Kunci: atmosfer ritel, promosi, emosi, impulse buying

\begin{abstract}
The purpose of this study was to explain the influence of the retail atmosphere, and the promotion of emotions, to explain the influence of the retail atmosphere, promotion, and emotions on impulse buying, to explain the role of emotions as mediating the relationship between the retail atmosphere and promotion of impulse buying at Hypermart Mall Bali consumers. Galeria. The population in this study were all consumers who had shopped at Hypermart Mall Bali Galeria and had done Impulse Buying. The sampling method used was purposive sampling. The samples selected in this study were 108 respondents. Data were analyzed using path analysis techniques. Based on the results of the study shows that the retail atmosphere, and promotion has a positive effect on emotions. Retail atmosphere, promotion, and emotions have a positive effect on impulse buying. Emotions mediate the relationship between the retail atmosphere and promotion of impulse buying on Hypermart Mall Bali Galeria consumers.
\end{abstract}

Keywords: retail atmosphere, promotion, emotion, impulse buying 


\section{PENDAHULUAN}

Keberhasilan globalisasi ekonomi dunia yang diiringi dengan kemajuan teknologi informasi telah memacu pertumbuhan industri ritel seluruh dunia (Lamba, 2003). Toko-toko ritel besar telah merambah ke seluruh dunia melalui jaringan distribusinya yang berperan sebagai wholesaler sekaligus sebagai retailer di semua negara berkembang termasuk Indonesia. Perkembangan gaya hidup masyarakat Indonesia yang semakin meningkat menggeser pusat perbelanjaan tradisional ke arah pusat perbelanjaan modern. Para pelaku bisnis pusat perbelanjaan berlomba-lomba untuk mengembangkan inovasi seperti peningkatan kualitas layanan pelanggan, penyediaan gerai, perencanaan desain pusat perbelanjaan, penyediaan sarana relaksasi bagi pengunjung, maupun penyediaan pusat jajanan yang dikemas dalam sebuah penyajian konsep pusat perbelanjaan. Semua itu adalah usaha yang dilakukan oleh para pengelola pusat perbelanjaan untuk memperpanjang jangka waktu dan frekuensi konsumen dalam pengalaman berbelanja.

Keinginan masyarakat untuk berbelanja dengan mudah dan nyaman menjadi salah satu faktor meningkatnya industri bisnis ritel di Indonesia. Bangkitnya bisnis ritel tradisional seperti pasar, warung, dan toko maupun bisnis ritel modern seperti supermarket, hypermarket, minimarket, convenience centre, superstore, factory outlet, dan department store sudah sewajarnya para pelaku bisnis ritel dituntut untuk mampu bersaing memperoleh pangsa pasar serta mempertahankan keberlanjutan usahanya dalam jangka panjang. Pertumbuhan penjualan ritel Indonesia dilaporkan sebesar 3,4\% pada april 2018, rekor ini naik dibanding 
sebelumnya yaitu 2,5\% untuk maret 2018. Data pertumbuhan penjualan ritel Indonesia diperbaharui bulanan, dengan rata-rata 10,7\% dari januari 2011 sampai april 2018 (www.ceicdata.com).

Sebagai salah satu industri yang dinamis saat ini, pemilik bisnis retail, terutama yang berbasis toko (store basedretailing), harus mampu mengantisipasi perubahan-perubahan yang terjadi di dalam pasar dan dengan tanggap mengadaptasinya pada bisnis mereka sehingga selalu sesuai dengan life style. Bisnis retail harus dapat berinovasi dan berkesinambungan dalam merespon dinamika dalam cara pandang yang penuh terobosan dan inovasi.

Pembelian impulsif (impulsive buying) adalah perilaku berbelanja yang terjadi secara tidak terencana, tertarik secara emosional, di mana proses pembuatan keputusan dilakukan dengan cepat tanpa berpikir secara bijak dan pertimbangan terhadap keseluruhan informasi dan alternatif yang ada (Bayley dan Nancarrow, 1998). Studi yang dilakukan Mattila dan Wirtz (2008) menyebutkan bahwa jumlah pembelian impulsif yang terjadi di department store di Amerika Serikat mencapai 27 sampai 62 persen dari seluruh pembelian.

Shopping emotion adalah faktor penentu yang penting mempengaruhi perilaku konsumen dalam sejumlah konteks. Secara khusus, shopping emotion atau kondisi suasana hati konsumen dianggap sebagai variabel situasional yang mempengaruhi perilaku belanja seseorang (Dawson et al., 1990). Rentang emosi yang relevan terhadap perilaku konsumtif adalah perasaan cinta, benci, takut, bahagia, bosan, ragu, sombong, marah, sedih, serakah, bersalah, malu, dan kagum (Holbrook and Hirschman, 1982). Sebagaimana disebutkan di atas, pembelian 
barang berdasarkan keinginan mendadak seringkali diikuti dengan tahap emosional yang intens dan mengasumsikan sifat yang lebih hedonis (Holbrook dan Hirschman, 1982). Emosi adalah sebuah efek dari mood yang merupakan faktor penting konsumen dalam keputusan pembelian (Park et al., 2006). Secara khusus, emosi dan risiko yang dirasakan secara luas diketahui penentu penting dari perilaku konsumen, dan mereka diyakini prediktor penting dari impulse buying (Lee dan Yi, 2008). Kurniawan dan Kunto (2013) menyatakan, jika shopping emotion meningkat maka akan turut meningkatkan impulse buying konsumen. Shopping emotion yang dirasakan konsumen dipengaruhi oleh store atmosphere suatu gerai yang dapat menyebabkan konsumen merasa tertarik dan nyaman untuk berbelanja. Impulse buying memainkan peran penting bagi pengusaha untuk mencapai tujuan.

Promosi berkaitan dengan seluruh kegiatan yang dilakukan perusahaan dalam rangka mengomunikasikan kebaikan produknya dan membujuk konsumen untuk membeli produk tersebut (Erwin, 2011). Hasil penelitian yang dilakukan oleh Banerjee \& Sunetra (2012) menemukan bahwa kegiatan promosi melalui potongan harga dan diskon memicu terjadinya pembelian impulsif dan penelitian yang dilakukan oleh Tendai \& Chipunza (2009) memperlihatkan bahwa kupon dan voucher belanja mempengaruhi pembelian impulsif.

Tujuan dari promosi penjualan adalah untuk meningkatkan volume penjualan jangka pendek dengan menciptakan aktivitas-aktivitas promosi penjualan yang tepat untuk mendorong impulse buying. Seorang tenaga penjualan terlatih dapat menurunkan frustrasi dengan membimbing dan membantu 
konsumen dalam proses pembelian dan mengaktifkan perilaku impulse buying (Iqbal et al., 2014). Promosi yang paling mempengaruhi konsumen adalah periklanan, dimana pengaruh positif dari iklan dapat meningkatkan pemikiran untuk membeli barang oleh konsumen (Vishnu dan Raheem, 2013). Perilaku konsumen saat ini telah berubah menjadi lebih hemat, dimana konsumen menginginkan penekanan nilai lebih besar dan meningkatkan fokus pada kenyamanan (Rittipant et al., 2013). Promosi juga dilakukan untuk mempertahankan minat belanja konsumen untuk berbelanja pada toko tersebut, menawarkan produk baru yang terdapat pada toko tersebut, dan untuk menarik konsumen potensial yang belum pernah berbelanja ke toko tersebut agar perusahaan dapat meningkatkan penjualannya. Christina (2010:69) menjelaskan bahwa salah satu penyebab terjadinya pembelian impulsif adalah pengaruh stimulus dari tempat belanja tersebut, dan Maymand \& Mostafa (2011) lingkungan stimulasi termasuk dalam rangsangan eksternal dimana rangsangan eksternal pembelian impulsif mengacu pada rangsangan pemasaran yang dikontrol dan dilakukan oleh pemasar melalui kegiatan merchandising, promosi, dan penciptaan suasana lingkungan toko. Media promosi disini berperan cukup besar dalam membentuk emosi seorang konsumen. Penggunaan media ini adalah untuk mendorong seseorang untuk membeli produk yang bukan mereka butuhkan namun yang mereka inginkan.

Faktor lain yang mempengaruhi pembelian impulsif yaitu faktor dari luar diri konsumen yang meliputi suasana dari lingkungan belanja itu sendiri. Pelanggan yang merasa nyaman dengan lingkungan toko ditambah dengan 
motivasi emosional maka akan memungkinkan meningkatnya pembelian secara impulsif (Yistiani dkk., 2012). Salah satu strategi pemasaran yang dapat dilakukan retailer adalah dengan menciptakan store atmosphere yang nyaman agar dapat memberikan kesan menarik kepada konsumen sehingga dapat mempengaruhi konsumen untuk melakukan pembelian (Kotler dan Keller 2009). Konsumen saat ini lebih cerdas dengan memilih pusat perbelanjaan dengan atmosfer yang menyenangkan, aman, nyaman, serta memberikan perasaan puas dan terhibur setiap kali melakukan aktivitas berbelanja. Perasaan senang yang dialami oleh konsumen ketika melakukan aktivitas berbelanja merupakan sebuah peluang bagi para pengelola gerai. Semakin lama dan semakin puas konsumen berada dalam gerai tersebut, maka hal ini diharapkan akan mendorong konsumen untuk melakukan pembelanjaan. Peluang ini dapat tercipta ketika pihak gerai tersebut dapat menciptakan atmosfer gerai yang menyenangkan agar para pengunjung gerai, betah berlama-lama berada di gerai dan diharapkan ada tindakan lanjutan yaitu konsumen membelanjakan uangnya (aspek hedonisme).

Hypermart Mall Bali Galeria bisa dikatakan Hypermart yang sering memberikan diskon, menyediakan lapangan parkir yang luas, keramahan para karyawan dalam melayani konsumen dan merupakan perusahaan ritel yang menyediakan segala jenis kebutuhan sehari-hari, hal inilah mendasari banyak yang melakukan pembelanjaan di Hypermart Mall Bali Galeria. Survey pendahuluan yang dilakukan terhadap 30 orang responden yang mengunjungi Hypermart Mall Bali Galeria, diperoleh hasil bahwa keseluruhan konsumen pernah melakukan impulse buying pada saat berbelanja pada Hypermart Mall Bali 
Galeria. 57\% responden menyatakan bahwa promosi berpengaruh meningkatkan impulse buying dan 33\% responden lainnya menyatakan susasana toko yang nyaman mampu meningkatkan impulse buying dan $10 \%$ orang responden menyatakan bahwa promosi dan suasana toko tidak berpengaruh terhadap impulse buying,hal ini mengindikasikan bahwa fenomena impulse buying selalu terjadi pada saat konsumen berbelanja di Hypermart Mall Bali Galeria.

Hasil penelitian yang dilakukan oleh (Yistiani dkk., 2012) menunjukkan bahwa store atmosphere berpengaruh positif dan signifikan terhadap pembelian impulsif dimana semakin baik gerai yang diciptakan akan dapat mendorong terjadinya pembelianimpulsif. Hasil penelitian dari Tendai dan Crispen (2009), yang menunjukkan bahwa store atmosphere memiliki pengaruh yang signifikan terhadap impulse buying. Penelitian yang dilakukan oleh Kurniawan dan Kunto (2013) di Matahari Department Store cabang Supermall Surabaya juga memperlihatkan hasil bahwa store atmosphere berpengaruh positif dan signifikan terhadap pembelian impulsif. Sari (2014) dalam penelitiannya di Tiara Dewata supermarket Denpasar juga menunjukkan bahwa store atmosphere berpengaruh positif dan signifikan terhadap pembelian impulsif. Berdasarkan pemaparan di atas, maka diajukan hipotesis pertama yaitu:

$\mathrm{H}_{1}$ : Atmosfer ritel berpengaruh positif terhadap impulse buying

Lovelock dan Wirtz (2004: 138) menyatakan bahwa, promosi penjualan (sales promotion) mempunyai tujuan memotivasi konsumen untuk membeli, artinya adanya perilaku konsumen dalam membeli yang melibatkan emosi konsumen. Emosi ini timbul karena adanya daya tarik atas sentimen atau gairah 
tertentu. Kondisi ini timbul karena adanya desakan untuk memenuhi kebutuhan hidup dengan cepat. Cummins dan Mullin (2004:41-44) mengungkapkan bahwa salah satu tujuan dari promosi penjualan adalah menciptakan ketertarikan dan mengalihkan perhatian pada harga. Ketertarikan itu akan menimbulkan gairah atau antusiasme konsumen untuk membeli suatu produk dan tetap membeli kepada gerai yang bersangkutan. Promosi terhadap nilai yang menciptakan ketertarikan dan mengakibatkan impulse buying. Promosi menimbulkan suatu kegairahan untuk membeli merupakan suatu rangsangan tingkah laku untuk memuaskan kebutuhan hidup (Fiske, 2007:245).

Berdasarkan hasil penelitian dari Kumiawan dan Kunto (2013), promosi berpengaruh positif dan signifikan pada Impulse Buying. Penelitian yang dilakukan oleh Sari dan Suryani (2014) yang menyatakan bahwa semakin baik kegiatan promosi yang dilakukan akan meningkatkan pembelian impulsif. Semakin tinggi tingkat promosi maka akan semakin tinggi juga keputusan impulse buying (Putra, 2014).

$\mathrm{H}_{2}$ : Promosi berpengaruh positif terhadap impulse buying.

Tingkah laku manusia dipengaruhi oleh lingkungan sekitamya. Penciptaan Atmosfer ritel yang baik akan dirasa nyaman oleh konsumen sehingga dapat berpengaruh secara langsung pada emosional konsumen saat berada di dalam gerai. Suasana di luar toko, suasana di toko-toko dalam, toko tata letak, dan toko hiasan interior yang merupakan komponen dari toko suasananya bisa membangkitkan kenikmatan, pelanggan pelanggan gairah, dan rasa kebebasan pelanggan atau dominasi saat konsumen berada di toko. Hal ini sesuai dengan 
pernyataan Mowen dan Minor (2002), bahwa toko suasananya mempengaruhi pembelanja emosional, yang kemudian mendorong untuk menopang atau mengekang belanja. Chang et al. (2009) menyimpulkan bahwa emosional kondisi store mempengaruhi konsumen yang akan menyebabkan degradasi. Perasaan emosional akan membuat dua orang dominan, yaitu euforia dan membangkitkan keinginan, keduanya muncul dari hobi atau keinginan yang merupakan dorongan mendadak (Chang et al., 2009). Dengan demikian konsumen yang bertumbuh dan persepsi akan berbelanja suasananya, maka akan menjadi pelanggan emosional yang lebih baik.

Berdasarkan hasil penelitian Kurniawati dan Restuti (2014), Store Atmosphere berpengaruh positif dan signifikan terhadap shopping emotion. Menurut hasil penelitian Kurniawan dan Kunto (2013), Store Atmosphere memiliki hubungan yang positif dan signifikan terhadap shopping emotion. Didukung juga oleh hasil penelitian Madjid (2014) bahwa Store Atmosphere memiliki pengaruh positif dan signifikan terhadap shopping emotion.

$\mathrm{H}_{3}$ : Atmosfer ritel berpengaruh positif terhadap shopping emotion

Promosi adalah suatu komunikasi informasi penjual dan pembeli yang bertujuan untuk merubah sikap dan tingkah laku pembeli, yang sebelumnya tidak mengenal menjadi mengenal sehingga menjadi membeli dan mengingat produk tersebut. Berdasarkan hasil penelitian dari Kumiawan dan Kunto (2013), promosi berpengaruh positif dan signifikan pada shopping emotion. Menurut hasil penelitian Kumiawati dan Restuti (2014) promosi memiliki pengaruh yang positif dan signifikan terhadap shopping emotion. 
$\mathrm{H}_{4}$ : Promosi berpengaruh positif terhadap shopping emotion

Seseorang konsumen yang sedang mengalami atau memiliki emosi cenderung akan melakukan impulse buying. Seorang konsumen sedang mengalami atau memiliki emosi yang negatif lebih cenderung mendorong konsumen untuk tidak melakukan impulse buying. Untuk mengukur emosi yang dikaitkan dengan konsumsi atau di dominasi lainnya, salah satunya adalah melalui kemampuan untuk mengkategorikan atau mengklasifikasikan emosi dan membedakannya dari bagian lain (Putra, 2014).

Berdasarkan hasil penelitian Kurniawati dan Restuti (2014), Shopping Emotion berpengaruh positif dan signifikan terhadap impulse buying. Menurut hasil penelitian Kurniawan dan Kunto (2013), Shopping Emotion memiliki pengaruh positif dan signifikan terhadap impulse buying. Theresia (2014) juga mengungkapkan dalam hasil penelitiannya bahwa Shopping Emotion memiliki pengaruh yang positif dan signifikan terhadap impulse buying. Berdasarkan pemaparan di atas, maka diajukan hipotesis kelima yaitu $\mathrm{H}_{5}$ : Shopping Emotion berpengaruh positif terhadap impulse buying

Penelitian yang di lakukan oleh Hetharie (2011) yang menyatakan bahwa emosi menghasilkan pengaruh positif sebagai variabel intervening antara pengaruh atmosfer gerai terhadap impulse buying. Hasil penelitian tersebut didukung oleh penelitian Margana (2014) menyatakan bahwa pembelian impulsif dipengaruhi oleh stimulus lingkungan toko dan faktor sosial toko yang dimediasi oleh emosi yang dirasakan konsumen. Berdasarkan pemaparan di atas, maka diajukan hipotesis keenam yaitu: 
$\mathrm{H}_{6}$ : Shopping emotion memediasi atmosfer ritel terhadap impulse buying

Atmosfer ritel mempengaruhi keadaan emosi pembeli yang menyebabkan atau mempengaruhi pembelian. Keadaan emosional akan membuat dua perasaan yang dominan yaitu perasaan senang dan membangkitkan keinginan (Kurniawan dan Kunto, 2013). Suasana gerai direncanakan sesuai dengan pasar sasarannya dan dapat menarik konsumen untuk melakukan pembelian Kotler dan Keller (2009). Adanya Atmosfer ritel yang menarik minat konsumen akan meningkatkan emosi, hal tersebut akan memicu timbulnya impulse buying.

Hasil penelitian Madjid (2014) bahwa atmosfer ritel memiliki pengaruh positif dan signifikan terhadap emosi. Penelitian yang di lakukan oleh Kurniawan dan Kunto (2013) yang menyatakan bahwa emosi menghasilkan pengaruh positif sebagai variabel intervening antara pengaruh promosi terhadap Impulse Buying.

$\mathrm{H}_{7}$ : Shopping emotion memediasi pengaruh promosi terhadap impulse buying

\section{METODE PENELITIAN}

Penelitian ini menggunakan pendekatan kuantitatif yang berbentuk asosiatif yaitu untuk menguji hubungan variabel yaitu Atmosfer ritel terhadap impulse buying, pengaruh promosi terhadap impulse buying, pengaruh variabel atmosfer ritel terhadap shopping emotion, pengaruh variabel promosi terhadap shopping emotion, variabel shopping emotion terhadap impulse buying, serta peran shopping emotion dalam memediasi atmosfer ritel terhadap impulse buying, dan peran shopping emotion dalam memediasi promosi terhadap impulse buying konsumen Hypermart Mall Bali Galeria. 
Lokasi penelitian dilakukan di Hypermart Mall Bali Galeria yang beralamat di Simpang Dewa Ruci Jalan By Pass Ngurah Rai, Kuta, Badung. Adapun alasan dari pemilihan lokasi penelitian tersebut adalah Hypermart Mall Bali Galeria merupakan salah satu tempat perbelanjaan modern yang menyediakan beraneka ragam barang dagangan. Hypermart Mall Bali Galeria memiliki fasilitas yang memadai seperti parkir yang luas, tempat bermain untuk anak- anak, dll, sehingga konsumen memilih Hypermart Mall Bali Galeria sebagai tujuan untuk berbelanja, karena fasilitas yang memadai akan menimbulkan emosi yang positif sehingga peluang konsumen melakukan impulse buying semakin besar. Hypermart Mall Bali Galeria terletak di simpang dewa ruci sehingga mudah dijangkau oleh konsumen. Hypermart Mall Bali Galeria mendukung variabel yang digunakan dalam penelitian ini contohnya promosi. Sedangkan obyek dalam penelitian ini adalah peran shopping emotion dalam memediasi pengaruh atmosfer ritel dan promosi terhadap impulse buying di Hypermart Mall Bali Galeria.

Variabel bebas dalam penelitian ini adalah atmosfer ritel (X1) dan promosi (X2). Variabel terikat dalam penelitian ini adalah impulse buying (Y2). Sedangkan variabel mediasi dalam penelitian ini adalah shopping emotion (Y1). Skala pengukuran yang digunakan dalam penelitian ini menggunakan metode skala likert.

Jenis data yang digunakan dalam penelitian ini adalah data kuantitatif berupa jumlah responden penelitian. Data kualitatif berupa hasil kuesioner dari responden. Sedangkan sumber data yang digunakan dalam penelitian ini adalah data primer diperoleh dari jawaban responden terhadap kuesioner tentang variabel 
penelitian yang akan diuji. Data sekunder didapat dari Hypermart Mall Bali Galeria mengenai gambaran umum, data juga diambil dari berita-berita online, dan studi empiris yang berkaitan dengan variabel atmosfer ritel, promosi, shopping emotion, dan impulse buying.

Populasi dalam penelitian ini adalah seluruh konsumen yang pernah berkunjung, melakukan impulse buying, dan berbelanja minimal 2 kali dalam 6 bulan terakhir di Hypermart Mall Bali Galeria. Metode pengambilan sampel yang digunakan adalah non-probability sampling (purposive sampling) yaitu teknik penentuan sampel dengan pertimbangan tertentu. Untuk jumlah sampel yang ideal adalah 5-10 kali jumlah variabel atau indikator. Jumlah indikator dalam penelitian ini adalah 18 buah. Jadi jumlah sampel yang digunakan sebanyak 108 sampel.

Metode pengumpulan data yang digunakan dalam penelitian ini adalah melalui wawancara langsung dengan menggunakan alat bantu kuesioner kepada responden untuk memperoleh data yang dibutuhkan. Proses wawancara akan dilakukan terhadap responden yang pernah melakukan pembelian di Hypermart Mall Bali Galeria. Penelitian ini menggukanan teknik analisis jalur. Koefisien jalur dapat diperoleh dengan dua persamaan struktural, yaitu persamaan regresi yang menunjukkan hubungan yang telah dihipotesiskan. Dua persamaan struktural tersebut ialah:

$$
\begin{aligned}
& \mathrm{Y}_{1}=p y_{1} x_{1}+\varepsilon_{1} \ldots \ldots \ldots \ldots \ldots \ldots \ldots \ldots \ldots \ldots \ldots \ldots \ldots \ldots \ldots \ldots \ldots \ldots \ldots n \\
& \mathrm{Y}_{2}=p y_{2} x_{1}+p y_{2} x_{2}+p y_{2} y_{1}+p y_{2} y_{1} y_{2}+\varepsilon_{2}
\end{aligned}
$$




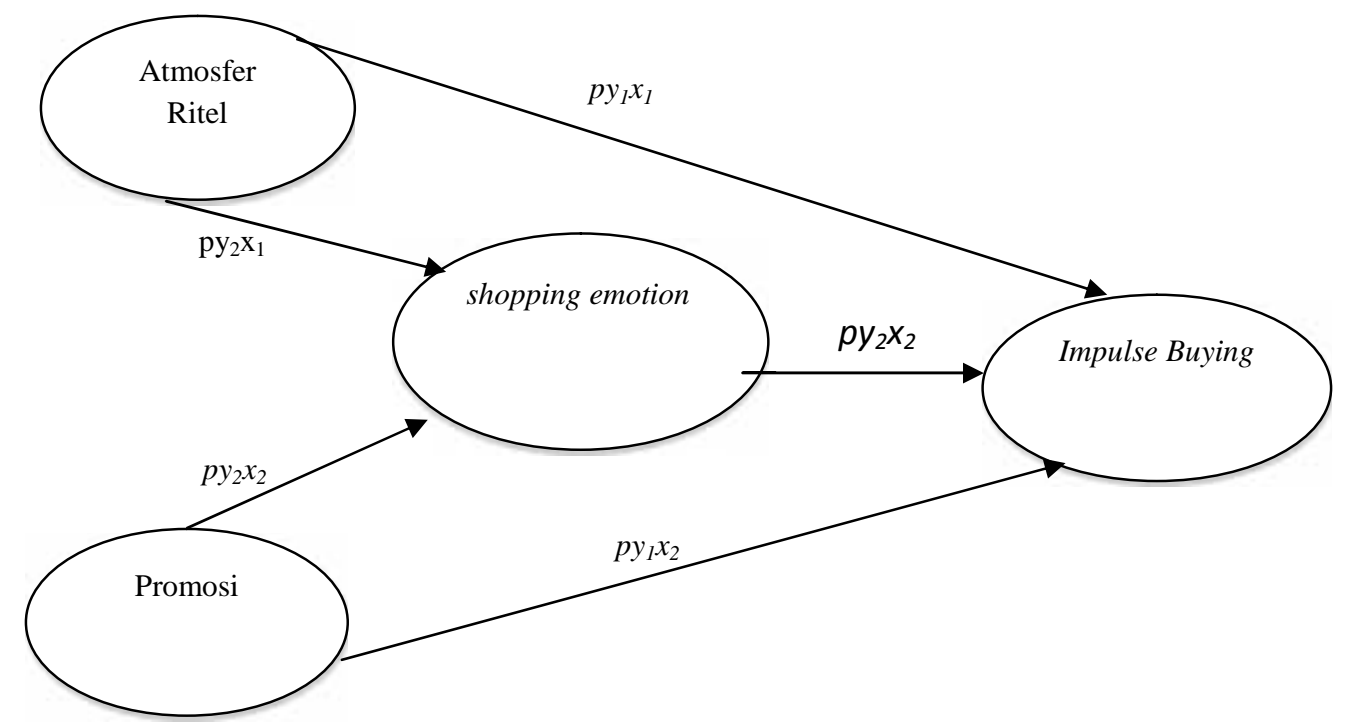

\section{Gambar 1. Diagram Jalur Penelitian}

Uji Sobel digunakan dengan menguji kekuatan pengaruh tidak langsung variabel atmosfer ritel $\left(\mathrm{X}_{1}\right)$ terhadap variabel impulse buying $\left(\mathrm{Y}_{2}\right)$ melalui variabel shopping emotion $\left(\mathrm{Y}_{1}\right)$ dan promosi $\left(\mathrm{X}_{2}\right)$ terhadap variabel impulse buying $\left(\mathrm{Y}_{2}\right)$ melalui variabel shopping emotion $\left(\mathrm{Y}_{1}\right)$. Berdasarkan diagram jalur pengaruh tidak langsung, maka dapat dihitung standar error koefisien a dan b ditulis dengan $\mathrm{S}_{\mathrm{a}}$ dan $\mathrm{S}_{\mathrm{b}}$, besarnya standar error tidak langsung (indirect effect) $\mathrm{S}_{\mathrm{ab}}$ dihitung dengan rumus:

$$
S_{\mathrm{ab}}=\sqrt{b^{2} S_{a}^{2}+a^{2} S_{b}^{2}+S_{a}^{2} S_{b}^{2}}
$$

Apabila hasil nilai perhitungan $Z>1,96$ (tingkat kepercayaan 95 persen), maka variabel intervening dianggap secara signifikan memediasi hubungan antara variabel eksogen dan variabel endogen.

\section{HASIL DAN PEMBAHASAN}


Karakteristik responden penelitian mengenai pengaruh atmosfer ritel dan promosi terhadap impulse buying yang dimediasi emosi pada Hypermart Mall Bali Galeria dapat dilihat dari beberapa kriteria yaitu: jenis kelamin, umur, pendidikan terakhir, jenis pekerjaan dan pendapatan perbulan. Berikut disajikan karakteristik responden dari berbagai kriteria tersebut.

Tabel 1.

Karakteristik Responden

\begin{tabular}{|c|c|c|c|c|}
\hline No & Variabel & Klasifikasi & Jumlah & Persentase (\%) \\
\hline \multirow[t]{3}{*}{1} & \multirow[t]{2}{*}{ Jenis Kelamin } & Laki-laki & 43 & 39,8 \\
\hline & & Perempuan & 65 & 60,2 \\
\hline & \multicolumn{2}{|c|}{ Jumlah } & 108 & 100 \\
\hline \multirow[t]{6}{*}{2} & \multirow[t]{5}{*}{ Usia } & $17-24$ Tahun & 23 & 21,3 \\
\hline & & $25-34$ Tahun & 39 & 36,1 \\
\hline & & $35-44$ Tahun & 27 & 25 \\
\hline & & $45-54$ Tahun & 16 & 14,9 \\
\hline & & $>55$ Tahun & 3 & 2,7 \\
\hline & \multicolumn{2}{|c|}{ Jumlah } & 108 & 100 \\
\hline \multirow[t]{5}{*}{3} & \multirow{4}{*}{ Pendidikan Terakhir } & SMA & 18 & 16,7 \\
\hline & & Diploma & 39 & 36,1 \\
\hline & & S1 & 43 & 39,8 \\
\hline & & Pasca Sarjana & 8 & 7,4 \\
\hline & \multicolumn{2}{|c|}{ Jumlah } & 108 & 100 \\
\hline \multirow[t]{6}{*}{4} & \multirow[t]{5}{*}{ Jenis Pekerjaan } & Pelajar/Mahasiswa & 14 & 13 \\
\hline & & Karyawan Swasta & 42 & 38,8 \\
\hline & & PNS & 23 & 21,3 \\
\hline & & Wirausaha & 29 & 26,9 \\
\hline & & Pelajar/Mahasiswa & 14 & 13 \\
\hline & \multicolumn{2}{|c|}{ Jumlah } & 108 & 100 \\
\hline \multirow[t]{6}{*}{5} & \multirow[t]{5}{*}{ Pendapatan } & $<1.000 .000$ & 0 & 0 \\
\hline & & $1.000 .000-2.999 .999$ & 3 & 2,8 \\
\hline & & $3.000 .000-4.999 .999$ & 7 & 6,5 \\
\hline & & $5.000 .000-7.000 .000$ & 17 & 15,7 \\
\hline & & $>7.000 .000$ & 81 & 75 \\
\hline & \multicolumn{2}{|c|}{ Jumlah } & 108 & 100 \\
\hline
\end{tabular}

Sumber: Data primer diolah, 2018

Tabel 1. menunjukkan responden dalam pada penelitian ini lebih banyak perempuan yaitu perempuan dengan jumlah 65 atau 60,2\% dan laki-laki sebanyak 43 dengan persentase $39,8 \%$. Karena pada umumnya dalam membeli barangbarang dan makanan untuk kebutuhan sehari-hari atau rumah tangga cenderung 
lebih banyak perempuan. Berdasarkan umur responden dapat diketahui bahwa jumlah responden yang berumur 25-34 memiliki jumlah paling banyak yaitu sebanyak 39 dengan persentase $36,1 \%$ dan paling sedikit pada responden dengan usia $>55$ tahun sebanyak 3 dengan persentase $2,7 \%$. Karena pada rentang usia ini seseorang dikategorikan pada usia produktif dan sudah memiliki pendapatan, sehingga akan lebih memilih untuk berbelanja di Hypermart Mall Bali Galeria.

Berdasarkan pendidikan terakhir menunjukan bahwa responden dengan pendidikan S1 mendominasi dengan jumlah 43 dengan persentase 39,8\% dan paling sedikit pada responden dengan pendidikan Pasca Sarjana yaitu sebanyak 8 dengan persentase 7,4\%. Karena seseorang dengan pendidikan S1 memiliki kemampuan dalam mengelola dana sehingga mampu menggunakan pendapatannya untuk berberlanja di Hypermart Mall Bali Galeria. Berdasrkan jenis pekerjaan responden dengan pekerjaan karyawan swasta memiliki jumlah paling tinggi yaitu sebanyak 42 dengan persentase $38,8 \%$ dan paling sedikit pada responden dengan pekerjaan pelajar yaitu sejumlah 14 atau 13\%. Karena pekerjaan sebagai karyawan swasta di sumsikan memiliki penghasilan lebih tinggi dan memiliki penghasilan tetap, sehingga dengan penghasilan seseorang mampu mengelola dan menggunakannya untuk berbelanja di Hypermart Mall Bali Galeria. Berdasarkan pendapatan responden dengan pendapatan $>7.000 .000$ memiliki jumlah paling tinggi yaitu sebanyak 81 dengan persentase $75 \%$ dan paling sedikit pada responden dengan pendapatan $<1.000 .000$ yaitu sejumlah 0 . Karena responden dengen penghasilan $>7.000 .000$ disumsikan sudah memiliki 
cukup pendapatan untuk bisa digunakan berbelanja di Hypermart Mall Bali Galeria.

Uji validitas bertujuan untuk mengukur pertanyaan-pertanyaan kuesioner yang harus dibuang atau diganti karena dianggap tidak relevan. Item instrumen dianggap valid jika lebih $\geq 0,3$. Berikut adalah hasil uji validitas.

Tabel 2.

Hasil Uji Validitas Instrumen Penelitian

\begin{tabular}{cccc}
\hline Variabel & Indikator & Koefisien Korelasi & Keterangan \\
\hline Atmosfer Ritel $\left(\mathrm{X}_{1}\right)$ & $\mathrm{X}_{1.1}$ & 0,844 & Valid \\
& $\mathrm{X}_{1.2}$ & 0,774 & Valid \\
& $\mathrm{X}_{1.3}$ & 0,769 & Valid \\
& $\mathrm{X}_{1.4}$ & 0,792 & Valid \\
Promosi $\left(\mathrm{X}_{2}\right)$ & $\mathrm{X}_{1.5}$ & 0,814 & Valid \\
& $\mathrm{X}_{2.1}$ & 0,817 & Valid \\
& $\mathrm{X}_{2.2}$ & 0,820 & Valid \\
& $\mathrm{X}_{2.3}$ & 0,791 & Valid \\
& $\mathrm{X}_{2.4}$ & 0,810 & Valid \\
shopping emotion $\left(\mathrm{Y}_{1}\right)$ & $\mathrm{Y}_{1.1}$ & 0,835 & Valid \\
& $\mathrm{Y}_{1.2}$ & 0,741 & Valid \\
& $\mathrm{Y}_{1.3}$ & 0,807 & Valid \\
& $\mathrm{Y}_{1.4}$ & 0,837 & Valid \\
& $\mathrm{Y}_{1.5}$ & 0,809 & Valid \\
& $\mathrm{Y}_{1.6}$ & 0,773 & Valid \\
& $\mathrm{Y}_{2.1}$ & 0,871 & Valid \\
& $\mathrm{Y}_{2.2}$ & 0,827 & Valid \\
& $\mathrm{Y}_{2.3}$ & 0,869 & Valid
\end{tabular}

Sumber: Data primer diolah, 2018

Hasil uji validitas pada Tabel 2. menunjukkan bahwa seluruh instrumen penelitian yang digunakan untuk mengukur variabel atmosfer ritel, promosi, shopping emotion dan impulse buying memiliki nilai koefisien korelasi dengan skor total seluruh item pernyataan lebih besar dari 0,30 dengan signifikansi kurang dari 0,05 . Hal ini menunjukkan bahwa butir-butir pernyataan dalam instrument penelitian tersebut valid dan layak digunakan sebagai instrument penelitian. 
Uji reliabilitas mampu menunjukan sejauh mana instrument dapat dipercaya dan diharapkan. Nilai suatu instrument dikatakan reliable apabila nilai Alpha Cronbach $\geq 0,6$. Hasil uji reliabilitas dapat dilihat pada Tabel 3 .

Tabel 3.

Hasil Uji Reliabilitas Instrumen Penelitian

\begin{tabular}{clcc}
\hline No. & \multicolumn{1}{c}{ Variabel } & Cronbadh's Alpha & Keterangan \\
\hline $\mathbf{1}$ & Atmosfer Ritel $\left(\mathrm{X}_{1}\right)$ & 0,858 & Reliabel \\
$\mathbf{2}$ & Promosi $\left(\mathrm{X}_{2}\right)$ & 0,822 & Reliabel \\
$\mathbf{3}$ & Shopping emotion $\left(\mathrm{Y}_{1}\right)$ & 0,888 & Reliabel \\
$\mathbf{4}$ & Impulse Buying $\left(\mathrm{Y}_{2}\right)$ & 0,814 & Reliabel \\
\hline
\end{tabular}

Sumber :Data primer diolah, 2018

Hasil uji reliabilitas yang disajikan dalam Tabel 3. menunjukkan bahwa seluruh instrumen penelitian memiliki koefisien Cronbach's Alpha lebih dari 0,60. Jadi dapat dinyatakan bahwa seluruh variabel telah memenuhi syarat reliabilitas atau sehingga dapat digunakan untuk melakukan penelitian.

Uji Kaiser Meyer Olkin digunakan untuk mengetahui kecukupan sampel. Analisis faktor dianggap layak jika besaran KMO memiliki nilai minimal 0,5. Dalam penelitian ini memperlihatkan semua variabel memiliki $\mathrm{KMO}>0,5$. Hal ini menyimpulkan bahwa masing-masing variabel memiliki kecukupan sampel untuk analisis faktor.

Kelayakan model uji faktor untuk masing-masing variabel dapat dilihat dari nilai Measures of Sampling Adequancy (MSA). Nilai MSA yang diperoleh dari masing-masing variabel besar dari 0,5 . Hal ini berarti masing-masing model layak digunakan dalam analisis faktor.

Hasil Percentage of Variance menjelaskan kemampuan dari masing-masing faktor untuk menjelaskan variasinya. Nilai Persentage of Variance masing-masing 
variabel sudah lebih besar dari 60 persen. Hal ini berarti faktor dari masingmasing variabel memiliki kelayakan untuk menjelaskan variabel faktornya.

Kelayakan model uji faktor untuk masing-masing variabel juga dapat dilihat dari nilai Loading Factor. Hasil analisis faktor konfirmatori dari variabel atmosfer ritel, promosi, emosi dan impulse buying menunjukan semua indikator konstruk tersebut mempunyai loading faktor dengan nilai diatas 0,5 . Dengan hasil ini, maka dapat dikatakan indikator-indikator pembentuk variabel atmosfer ritel, promosi, emosi dan impulse buying telah menunjukkan sebagai indikator yang kuat.

Berdasarkan hasil perhitungan koefisien regresi, nilai error dan determinasi total, maka dapat disusun diagram model analisis jalur seperti pada Gambar 2.

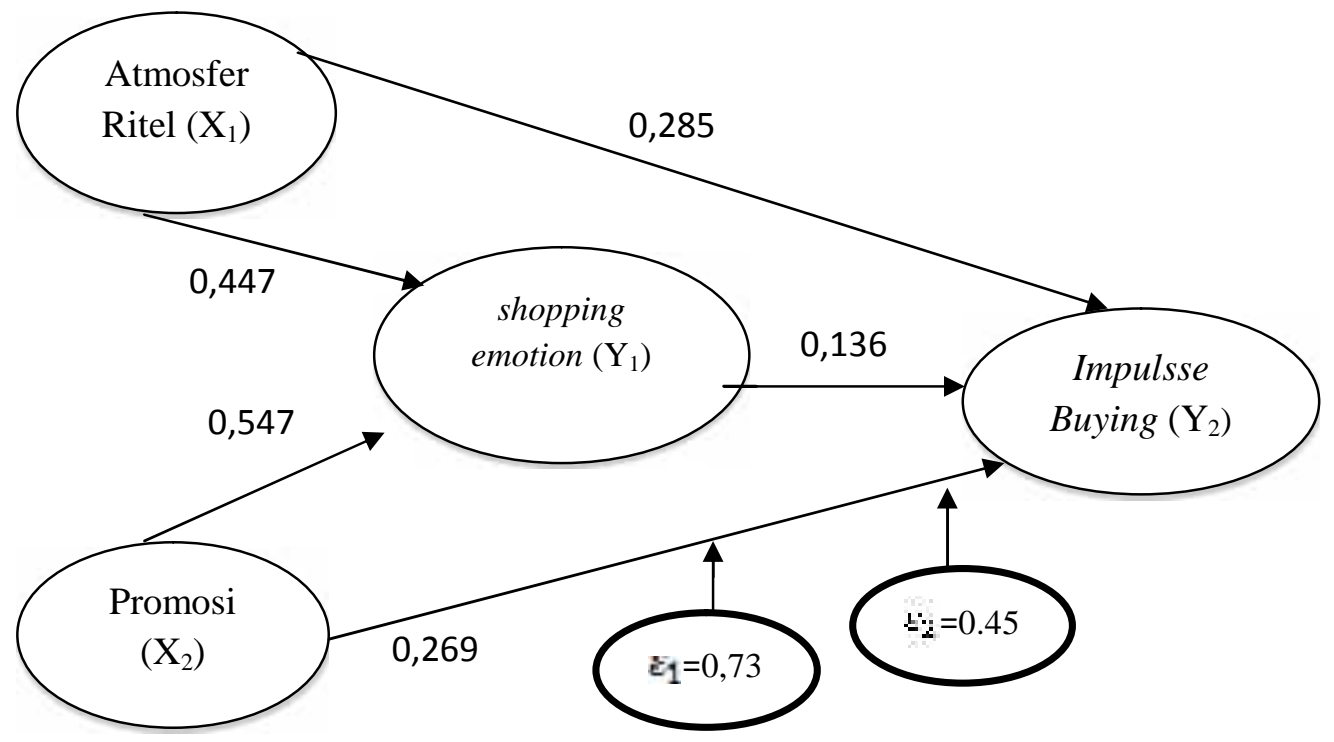

\section{Gambar 2.Model Diagram Jalur Akhir}

Berdasarkan diagram jalur pada Gambar 2., maka dapat dihitung besarnya pengaruh langsung dan pengaruh tidak langsung serta pengaruh total antar variabel. Perhitungan pengaruh antar variabel dirangkum dalam Tabel 4. 
Nilai determinasi total sebesar 0,889 mempunyai arti bahwa sebesar 88,9 persen variasi Impulse Buying dipengaruhi oleh variasi atmosfer ritel, promosi dan shopping emotion, sedangkan sisanya sebesar 11,1 persen djelaskan oleh faktor lain yang tidak dimasukkan ke dalam model.

Tabel 4.

Pengaruh Langsung dan Pengaruh Tidak Langsung serta Pengaruh Total Analisis Jalur Variabel Penelitian

\begin{tabular}{cccc}
\hline $\begin{array}{c}\text { Pengaruh } \\
\text { Variabel }\end{array}$ & $\begin{array}{c}\text { Pengaruh } \\
\text { Langsung }\end{array}$ & $\begin{array}{c}\text { Pengaruh Tidak Langsung Melalui Emosi } \\
(\mathbf{Y 1})(\boldsymbol{\beta} 1 \mathbf{x} \boldsymbol{\beta} 3)\end{array}$ & Pengaruh Total \\
\hline $\mathrm{X}_{1} \rightarrow \mathrm{Y}_{1}$ & 0,447 & - & 0,447 \\
$\mathrm{X}_{1} \rightarrow \mathrm{Y}_{2}$ & 0,285 & 0,060 & 0,345 \\
$\mathrm{Y}_{1} \rightarrow \mathrm{Y}_{2}$ & 0,136 & - & 0,136 \\
$\mathrm{X}_{2} \rightarrow \mathrm{Y}_{1}$ & 0,547 & - & 0,547 \\
$\mathrm{X}_{2} \rightarrow \mathrm{Y}_{2}$ & 0,269 & 0,074 & 0,343 \\
\hline
\end{tabular}

Sumber : Data primer diolah, 2018

Uji sobel digunakan untuk menguji signifikansi variabel emosi sebagai variabel mediasi dalam hubungan antara variabel atmosfer ritel dan impulse buying serta hubungan antara variabel promosi dan impulse buying dengan nilai masing-masing Z > 1,96 berarti variabel mediator shopping emotion dinilai secara signifikan memediasi pengaruh atmosfer ritel terhadap impulse buying dan memediasi pengaruh promosi terhadap impulse buying.

Hasil analisis menunjukkan bahwa atmosfer ritel berpengaruh positif dan signifikan terhadap impulse buying. Hal ini memiliki makna bahwa semakin baik atmosfer ritel di Hypermart Mall Bali Galeria, maka semakin meningkat pula impulse buying di Hypermart Mall Bali Galeria. Sebaliknya apabila atmosfer ritel di Hypermart Mall Bali Galeria kurang maka impulse buying di Hypermart Mall Bali Galeria akan menurun. 
Hasil tersebut mengindikasikan bahwa nilai-nilai yang terkandung dalam atmosfer ritel mampu dipersepsikan dengan baik dan berdampak nyata pada impulse buying di Hypermart Mall Bali Galeria. Atmosfer ritel yang diukur berdasarkan indikator :penataan cahaya, aroma, dekorasi, musik, tata ruang dan letak terbukti mampu meningkatkan impulse buying di Hypermart Mall Bali Galeria, hal ini dapat diartikan bahwa apabila atmosfer ritel di Hypermart Mall Bali Galeria terus ditata dengan baik, maka akan mampu memberikan kontribusi yang signifikan untuk meningkatkan impulse buying di Hypermart Mall Bali Galeria. Penelitian ini mendukung beberapa hasil penelitian sebelumnya dan konsisten dengan hasil penelitian yang dilakukan oleh Yistiani dkk. (2012), Tendai dan Crispen (2009), Kurniawan dan Kunto (2013) dan Sari (2014) menemukan bahwa atmosfer ritel berpengaruh positif sifnifikan terhadap impulse buying.

Hasil analisis menunjukkan bahwa promosi berpengaruh positif dan signifikan terhadap impulse buying. Hal ini memiliki makna bahwa semakin baik promosi di berikan Hypermart Mall Bali Galeria, maka semakin meningkat pula impulse buying di Hypermart Mall Bali Galeria . Sebaliknya apabila promosi yang diberikan Hypermart Mall Bali Galeria kurang maka impulse buying di Hypermart Mall Bali Galeria akan menurun.

Hasil tersebut mengindikasikan bahwa nilai-nilai yang terkandung dalam promosi mampu dipersepsikan dengan baik dan berdampak nyata pada impulse buying di Hypermart Mall Bali Galeria. Promosi yang diukur berdasarkan indikator :member card, cash back, buy 2 get 1, hadiah langsung terbukti mampu 
meningkatkan impulse buying di Hypermart Mall Bali Galeria, hal ini dapat diartikan bahwa apabila promosi yang berikan Hypermart Mall Bali Galeria terus dilakukan secara rutin, maka akan mampu memberikan kontribusi yang signifikan untuk meningkatkan impulse buying di Hypermart Mall Bali Galeria. Penelitian ini mendukung beberapa hasil penelitian sebelumnya dan konsisten dengan hasil penelitian yang dilakukan oleh Kumiawan dan Kunto (2013), Sari dan Suryani (2014) dan menemukan bahwa promosi berpengaruh positif sifnifikan terhadap impulse buying.

Hasil analisis menunjukkan bahwa atmosfer ritel berpengaruh positif dan signifikan terhadap shopping emotion. Hal ini memiliki makna bahwa semakin baik atmosfer ritel di Hypermart Mall Bali Galeria, maka semakin meningkat pula shopping emotion untuk melakukan pembelian di Hypermart Mall Bali Galeria. Sebaliknya apabila atmosfer ritel di Hypermart Mall Bali Galeria kurang maka shopping emotion untuk melakukan pembelian di Hypermart Mall Bali Galeria akan menurun.

Hasil tersebut mengindikasikan bahwa nilai-nilai yang terkandung dalam atmosfer ritel mampu dipersepsikan dengan baik dan berdampak nyata pada shopping emotion pelanggan di Hypermart Mall Bali Galeria. Atmosfer ritel yang diukur berdasarkan indikator: penataan cahaya, aroma, dekorasi, musik, tata ruang dan letak terbukti mampu meningkatkan shopping emotion pelanggan untuk melakukan pembelian di Hypermart Mall Bali Galeria, hal ini dapat diartikan bahwa apabila atmosfer ritel di Hypermart Mall Bali Galeria terus ditata dengan baik, maka akan mampu memberikan kontribusi yang signifikan untuk 
meningkatkan shopping emotion untuk berbelanja. Penelitian ini mendukung beberapa hasil penelitian sebelumnya dan konsisten dengan hasil penelitian yang dilakukan oleh Kurniawati dan Restuti (2014), Kurniawan dan Kunto (2013) dan Madjid (2014) menemukan bahwa atmosfer ritel berpengaruh positif sifnifikan terhadap shopping emotion.

Hasil analisis menunjukkan bahwa promosi berpengaruh dan signifikan terhadap shopping emotion. Hal ini memiliki makna bahwa semakin baik promosi di Hypermart Mall Bali Galeria, maka semakin meningkat pula shopping emotion untuk melakukan pembelian di Hypermart Mall Bali Galeria. Sebaliknya apabila promosi di Hypermart Mall Bali Galeria kurang maka shopping emotion untuk melakukan pembelian di Hypermart Mall Bali Galeria akan menurun.

Hasil tersebut mengindikasikan bahwa nilai-nilai yang terkandung dalam promosi mampu dipersepsikan dengan baik dan berdampak nyata pada shopping emotion pelanggan di Hypermart Mall Bali Galeria. Promosi yang diukur berdasarkan indikator: member card, cash back, buy 2 get 1 free, hadiah langsung terbukti mampu meningkatkan shopping emotion pelanggan untuk melakukan pembelian di Hypermart Mall Bali Galeria, hal ini dapat diartikan bahwa apabila promosi di Hypermart Mall Bali Galeria terus dilakukan secara rutin, maka akan mampu memberikan kontribusi yang signifikan untuk meningkatkan shopping emotion untuk berbelanja di Hypermart Mall Bali Galeria. Penelitian ini mendukung beberapa hasil penelitian sebelumnya dan konsisten dengan hasil penelitian yang dilakukan oleh Kumiawan dan Kunto (2013) dan Kumiawati dan 
Ni Putu Krisna Diah Rani, Peran Shopping Emotion...

Restuti (2014) menemukan bahwa promosi berpengaruh positif sifnifikan terhadap shopping emotion.

Hasil analisis menunjukkan bahwa shopping emotion berpengaruh dan signifikan terhadap impulse buying. Hal ini memiliki makna bahwa semakin baik shopping emotion pelanggan dalam melakukan interkasi di Hypermart Mall Bali Galeria, maka semakin meningkat pula impulse buying di Hypermart Mall Bali Galeria. Sebaliknya apabila shopping emotion pelanggan dalam melakukan interaksi di Hypermart Mall Bali Galeria kurang maka pembelian impulsif di Hypermart Mall Bali Galeria akan menurun.

Hasil tersebut mengindikasikan bahwa nilai-nilai yang terkandung dalam shopping emotion mampu dipersepsikan dengan baik dan berdampak nyata pada pembelian impulsif di Hypermart Mall Bali Galeria. Shopping emotion yang diukur berdasarkan indikator: senang, nyaman, puas, suka, tertarik, bersemangat terbukti mampu meningkatkan pembelian impulsif di Hypermart Mall Bali Galeria, hal ini dapat diartikan bahwa apabila perasaan konsumen saat melakukan interaksi di dalam gerai di Hypermart Mall Bali Galeria terus positif, maka akan mampu memberikan kontribusi yang signifikan untuk meningkatkan impulse buying di Hypermart Mall Bali Galeria. Penelitian ini mendukung beberapa hasil penelitian sebelumnya dan konsisten dengan hasil penelitian yang dilakukan oleh Kumiawan dan Kunto (2013), Theresia (2014) dan Kumiawati dan Restuti (2014) menemukan bahwa shopping emotion berpengaruh positif sifnifikan terhadap impulse buying. 
Berdasarkan hasil uji Sobel, ditemukan pengaruh yang positif antara variabel atmosfer ritel terhadap impulse buying melalui variabel shopping emotion, hal ini berarti pembelian tidak terencana akan semakin meningkat apabila konsumen merasakan atmosfer ritel yang nyaman dan didukung dengan perasaan shopping emotion konsumen saat melakukan interaksi di dalam gerai, maka kecenderungan konsumen untuk melakukan pembelian impulsif juga semakin besar.

Hasil penelitian ini didukung oleh penelitian yang dilakukan oleh Hetharie (2011), Margana (2014) yang menyatakan bahwa pembelian impulsif dipengaruhi oleh stimulus lingkungan toko dan faktor sosial toko yang dimediasi oleh shopping emotion yang dirasakan konsumen. Dengan demikian, apabila konsumen yang merasakan atmosfer ritel yang nyaman di Hypermart Mall Bali Galeria, lalu didukung dengan adanya shopping emotion konsumen berupa perasaan senang maka akan tercipta pembelian tidak berencana konsuemn di Hypermart Mall Bali Galeria

Berdasarkan hasil uji Sobel, ditemukan pengaruh yang positif antara variabel promosi terhadap impulse buying melalui variabel shopping emotion, hal ini berarti pembelian tidak terencana akan semakin meningkat apabila konsumen mendapat promosi yang menarik dengan didukung shopping emotion konsumen saat sedang akan melakukan pembelian, maka kecenderungan konsumen untuk melakukan pembelian impulsif juga semakin besar.

Hasil penelitian ini didukung oleh penelitian yang dilakukan oleh Kurniawan dan Kunto (2013), yang menyatakan bahwa shopping emotion 
menghasilkan pengaruh positif sebagai variabel intervening antara pengaruh promosi terhadap pembelian impulsive. Dengan demikian, bahwa dengan adanya penawaran promosi yang menarik dari Hypermart Mall Bali Galeria, lalu didukung dengan adanya shopping emotion konsumen berupa perasaan senang dan tertarik untuk melakukan pembelian, dapat semakin meningkatkan perilaku pembelian tidak terencana konsumen di Hypermart Mall Bali Galeria.

\section{SIMPULAN DAN SARAN}

Berdasarkan pembahasan hasil penelitian di atas, dapat disimpulkan bahwa Atmosfer ritel, promosi, dan shopping emotion berpengaruh positif dan signifikan terhadap impulse buying, Atmosfer ritel dan promosi berpengaruh positif dan signifikan terhadap shopping emotion, shopping emotion memediasi hubungan antara atmosfer ritel terhadap impulse buying, dan shopping emotion memediasi hubungan antara promosi terhadap impulse buying pada konsumen Hypermart Mall Bali Galeria. Sementara itu, saran yang dapat diberikan yaitu diharapkan pihak manajemen Hypermart Mall Bali lebih memperhatikan aroma dalam ruangan agar nantinya konsumen merasa senang dan nyaman, membuat member card yang dapat berfungsi secara efektif dan dapat digunakan sesuai harapan konsumen sehingga dapat mendorong timbulnya impulse buying. Selain itu sebaiknya Hypermart Mall Bali Galeria membuat inovasi kegiatan bagi konsumen dan selalu menyediakan produk yang dibutuhkan dan diinginkan konsumennya.

\section{REFERENSI}

Banerjee, S. and Sunetra, S. (2012). Impulse Buying Behaviour Retail Stores Triggering The Sense. Asia Pacific Journal of Marketing \& Management Review, 1(2), 1-21. 
Bayley, G. and Nancarrow, C. (1998). Impulse purchasing: a qualitative exploration of the phenomenon. Qualitative Market Research: An International Journal, 1(2), 99-114.

CEIC. (2018). Pertumbuhan Penjualan Ritel Indonesia. https://www.ceicdata.com/id/indicator/indonesia/retail-sales-growth. Diakses 11 Juli 2018.

Chang, E., Eckman, M., and Ym, R. (2009). Impulse Buying Behavior of Apparel: Application of S-O-R Model and Moderating Effect of Hdonic Motivation. ITAA Proceedings.

Christina, W. U. (2010). Manajemen Ritel: Strategi dan Implementasi Operasional Bisnis Ritel Modern di Indonesia. Edisi ke 2. Jakarta: Salemba Empat.

Cummins, J. dan Mullin, R. (2004). Sales Promotion Menciptakan Mengimplementasikan dan Mengintergrasikan program promosi penjualan (Hesti Widyanigrum, penerjemah) Jakarta: Penerbit PPM.

Dawson, S. B., Peter, H., and Ridgeway, N. R. (1990). Shopping Motive, Emotional States and Retail Outcome. Journal of Retailing, 66, 408-427.

Erwin, T. R. (2011). Pengaruh Faktor Harga, Promosi, dan Pelayanan Terhadap Keputusan Konsumen Untuk Belanja di Alfamart Surabaya. Jurnal Kewirausahaan Lembaga Penelitian dan Pengabdian Masyarakat Universitas Widya Kartika Surabaya, 5(2), 25-29.

Fiske, J. (2007). Cultural and Communication Studies. Yogyakarta: Jalasutra.

Hetharie, A. J. (2011). Peran Emosi Positif sebagai Mediator Stimulis Lingkungan Toko dan Faktor Sosial Terhadap Impulse Buying Tendency pada Matahari Departement Store Kota Ambon. Jurnal Aplikasi Manajemen, 10(4), 890898.

Holbrook, M. B. and Hirschman, E. C. (1982). The experiential aspects of consumption: consumer fantasies, feelings, and fun. Journal of Consumer Research, 9(2), 132-40.

Iqbal, A., Akhtar, S., and Lodhi, R. N. (2014). Determinants of Impulsive Buying for Clothing In Pakistan. British Journal of Marketing Studies, 2(8).

Kotler, P. dan Keller, K. L. (2009). Manajemen Pemasaran. Edisi 13. Jakarta: Erlangga. 
Kurniawan, D. dan Kunto, Y. S. (2013). Pengaruh Promosi dan Store Atmosphere Terhadap Impuls buying dengan Shoping Emotion Sebagai Variabel Intervening Studi Kasus di Matahari Departement Store Cabang Supermall Surabaya. Jurnal Manajemen Pemasaran, 1(2), 1-8.

Kurniawati, D. dan Restuti, S. (2014). Pengaruh Sales Promotion Dan Store Atmosphere Terhadap Shopping Emotion Dan Impulse Buying Pada Giant Pekanbaru. Jurnal Tepak Manajemen Bisnis, 6(3), 24-37.

Lamba, A. J. (2003). The Art of Retailing. Tata McGraw-Hill Publishing Company Limited, New Delhi India, 20-121.

Lee, G. Y. dan Yi, Y. (2008). The Effect of Shopping Emotions and Perceived Risk on Impulsive Buying: The Moderating Role of Buying Impulsiveness Trait. Seoul Journal of Business, 14(2).

Lovelock, C. and Wirtz, J. (2004). Service Marketing. fifth edition. Pearson Prentice Hal

Madjid, R. (2014). The Influence Store Atmosphere Towards Customer Emotions and Purchase Decisions. International Journal of Humanities and Social Science Invention, 3(10), 11-19.

Margana, C. A. dan Setiawan, P. Y. (2014). Pengaruh Stimulus Lingkungan Toko Terhadap Perilaku Pembelian Tidak Terencana yang Dimediasi oleh Emosi Positif. Jurnal Manajemen, 3(9), 2615-2632.

Mattila, A. S. dan Jochen, W. (2008). The role of store environmental stimulation and social factors on impulse purchasing. Journal of Services Marketing, 22(7), 562-567.

Maymand, M. M., and Mostafa, A. (2011). Impulse Buying: The Role of Store Environmental Stimulation and Situational Factors (An empirical investigation). African Journal of Business Management, 5(34), 1305713065.

Mowen, J. C., and Michael, M. (2002). Consumer Behavior. Fifth Edition. Harcourt, Inc.

Naentiana, P. V. dan Setiawan, P. Y. (2014). Peran Positive Emotion Dalam Memediasi Pengaruh Hedonic Shopping Value Terhadap Impulse Buying. Jurnal Nasional, 2314-2332.

Park, E. J., Kim, E. Y., and Forney, J. C. (2006). A Structural Model of FashionOriented Impulse Buying Behavior. Journal of Fashion Marketing and Management, 433 - 446. 
Putra, B. P. (2014). Analisis Pengaruh Promosi, Emosi Positif Dan Store Environment Terhadap Perilaku Impulse Buying. Diponegoro Journal of Management, 3(4), 1-11.

Rittipant, N. (2013). Thai Consumer Response To SalesPromotions For Personal Care Products. International Conference on Engineering, Project, and Production Management, 700-709.

Sari, T. A. D. dan Suryani, A. (2014). Pengaruh Merchandising, Promosi, dan Toko Terhadap Impulse Buying. Jurnal Manjemen, 3(4), 851-867.

Tendai, M. dan Chipunza, C. (2009). In-store Shopping Environment and Impulsive Buying. African Journal of Marketing Management, 1(4), 102108.

Theresia, V. M. (2014). Faktor-Faktor Yang Memengaruhi Pembelian Impulsif Pada Remaja Gereja GMIM Wilayah Manado Winangun. Jurnal Riset Bisnis dan Manajemen, 2(4), 60-72.

Vishnu, P. dan Raheem, A. R. (2013). Factors Influencing Impulse Buying Behavior. European Journal Of Scientific Research, 100(3).

Widiartaka, W. A. dan Purnami, N. M. (2014). Pengaruh Lingkungan Toko Dan Faktor Situasional Terhadap Perilaku Pembelian Tak Terencana Pada Matahari Department Store Denpasar. Jurnal Manajemen, 3(6).

Yistiani, M. N. N., Kerti, Y. N. N., dan Suasana, K. G. (2012). Pengaruh Atmosfer Gerai Dan Pelayanan Ritel Terhadap Nilai Hedonik Dan Pembelian Impulsif Pelanggan Matahari Department Store Duta Plaza Di Denpasar. Jurnal Manajemen Strategi Bisnis dan Kewirausahaan, 6(2), 139-149. 